\title{
Transforming Municipal Governance in Global Context: A Case Study of the Dialectics of Social Change
}

Daniel Robey, Georgia State University,USA, drobey@gsu.edu

Jonny Holmström, Center for Digital Business \& Department of Informatics, Umeå University,jjonny.holmstrom@informatik.umu.se

\section{ABSTRACT}

This paper presents a social analysis of the development and use of information technology to support the governance process in the municipal organization of Umeå, Sweden. The technology was intended to monitor and scrutinize organizational activities by paying closer attention to the resources required for public programs. Through its use, municipal managers hoped to increase the visibility of the economic consequences of decisions to fund particular social programs. In this paper, we analyze the implementation of the system at the organizational and institutional levels of social analyses. Employing a dialectic approach, which examines forces promoting and opposing social change, we explain how the tool was easily implemented in the organization but opposed by the community's citizens. Although the information system reinforced a new economic discourse and helped to make organizational members more accountable for their actions, the citizens protested the effects of the new economic discourse. By focusing simultaneously upon organizational and institutional influences, we can understand more completely how global pressures translate into organizational and societal change.

\section{KEY WORDS}

OLAP, Organizational Transformation, Institutional Theory, Globalization.

\section{INTRODUCTION}

On November 22 1999, thousands of demonstrators appeared at the gates of City Hall in Umeå, Sweden, protesting against the newly proposed cuts in the municipal budget for the coming year. The public was upset about the cost-saving efforts in the proposal and protested that the level of services offered to the public would suffer as a result of these efforts. The demonstrators were disappointed in the city managers for being too businesslike, neglecting due political processes and ignoring public sentiment. According to the protesters, community needs that were formerly debated democratically had seemingly become business decisions based on economic criteria.

The demonstration was the most fierce and dramatic of a series of public protests by citizens in Umeå against the budget proposal. On an earlier occasion, protesters staged their objections accompanied by children playing violins. The children and their parents were going to lose the publicly funded violin classes as a result of the 
proposed budget cuts, and the newspaper photographs of the deprived music students placed human faces on the issue.

Although the controversy in a small city in Northern Sweden may appear to bear little relevance outside of the local situation, a careful analysis of the case shows it to represent issues of global importance. Why would a small municipality in a country well known for its commitment to public welfare employ more economic criteria in evaluating public expenditures? How was an advanced tool for decision analysis successfully implemented in an organization that had enjoyed little exposure to computer-based systems of any kind? And what accounts for the public outcry over the use of decision tools to rationalize municipal management? These questions are addressed in this paper by combining organizational and institutional analysis. The organizational analysis focuses on the political process by which various actors in the municipal organization were persuaded to adopt and use the new decision tool. The institutional analysis focuses on the contemporary phenomenon of globalization and its attendant pressures on all organizations to become more efficient. By combining these analyses, we can achieve a more complete understanding of the way that globalization impinges on the management of information technology in public organizations.

The arguments used in analyzing the case follow a line of reasoning derived from recent critiques of the deterministic logic that is often used to explain the relation between information technology and social change. In particular, the paper employs a dialectical "logic of opposition" in both the organizational and institutional analyses (Robey and Boudreau, 1999). Using a logic of opposition addresses a concern that more deterministic theory, which posits organizational change as caused or "driven" by information technologies, has not successfully explained the extreme diversity of empirical results (Robey and Boudreau, 1999; 2000). Theories incorporating dialectical explanations for social change identify forces that promote and forces that oppose social change (Van de Ven and Poole, 1995). The outcomes of dialectical processes are difficult to predict, yet an understanding of such processes can account for a variety of observed outcomes. For these reasons, we adopt a dialectical approach in our analysis of the implementation and consequences of information technology in municipal governance.

\section{MUNICIPAL GOVERNANCE IN GLOBAL CONTEXT}

The experiences of local governments in all parts of the world can be appreciated more completely in the context of globalization. Globalization refers to the increased connection among individuals, organizations and societies that were previously separated (Walsham, 2001). In essence, the world has become a smaller place due to the capabilities of advanced technologies to transmit information from place to place. Global reach and interconnectivity are made possible largely through the use of new information technology. Social change is inseparable from the changes in the technological infrastructure through which many of the activities are carried out "...since technology is society and society cannot be understood or represented 
without its technological tools" (Castells, 1996, p. 5). Indeed, the ease of movement of information-based resources (especially money) serves to reduce the effectiveness of geographic and political barriers to trade. With an increased awareness of market and investment opportunities throughout the world, consumers and investors may operate without traditional local restrictions. As a result, resources including labor become more mobile in a less restricted global marketplace, and both private and public organizations face new pressures to become more efficient.

Thus, local communities like Umeå make local decisions in global context rather than operating in isolation from the rest of the world. In a real sense, Umeå and other cities must compete to attract and retain their populations from migrating to opportunities elsewhere. They must offer valuable services at lower cost or risk the departure of citizens to other cities and other countries. Indeed, Umeå's use of information technology is characteristic of the efforts to place social decisions under an economic microscope. As our case study will show, Umeå's managers adopted and successfully implemented an advanced Online Analytical Processing (OLAP) tool to help them make decisions by drilling down into their operating data. In this manner, they operated like business managers in any industry responding to global economic pressures by harnessing information technology in the guise of business process reengineering, knowledge management, data mining, and other such initiatives.

Despite these kinds of responses, however, globalization has not resulted in the homogenization of cultures or local traditions of governance (Dicken, 1992). As Walsham observes, "there is no strong evidence of any simple standardization of humanity" (2001, p. 21). More accurately, global pressures and local traditions coexist and often conflict with one another (Walsham and Sahay, 1999). Despite claims that sovereign nation states are increasingly irrelevant in a world with a single, interconnected capitalistic system, global pressures may breed local responses aimed to preserve traditional cultural and economic systems. Moreover, local governments are directly involved with formulating policies designed to regulate the degree and nature of global economic activity. According to Walsham, "the state is required to mediate between increasingly potent international pressures and heightened levels of domestic discontent from those affected negatively as a result of such pressures" (2001, p. 23).

Globalization has put socially democratic welfare states under enormous stress. Not only are public budgets tighter under the coercion of global financial markets, but also global corporations can take advantage of cost differentials in social benefits and standards in a way that public organization cannot. As a result, "welfare states are being downsized to the lowest common denominator that keeps spiraling downwards" (Castells, 1997, p. 254). The steady replacement of social ideals with corporate thinking has reduced many political questions to economic questions (Deetz, 1992). Thus, the shift towards globalization is accompanied by shifts in the evaluation of organizational activities to privilege economic criteria, thereby restricting the range of responses available to satisfy legitimate social needs. Nonetheless, social needs remain and demand some sort of reconciliation with the forces of global capitalism. 
Because of these opposing forces, the adoption of a more businesslike and more market-oriented approach to public management is not simple to analyze. Umeå's municipal managers sought to sustain their commitment to providing services to benefit public welfare, but they also began to base these decisions on economic criteria. Services benefiting small groups of constituents, such as Umeå's violin students, were the first targets of cost-cutting efforts. Because there was no true market mechanism operating to place a price on violin lessons, there was no simple way to compare the value of violin lessons with, say, the value of modernizing a residence for the elderly. Neither the children nor the elderly were prepared to pay directly for these services, so politicians were left to decide what was in the public interest.

To understand these opposing pressures, we need to choose social theories at both the organizational and institutional levels that accommodate opposition. In the next section, we discuss organizational politics and institutional theory as dialectical theories for explaining social change. We will use these theoretical tools to analyze the opposing forces in the case of Umeå's municipal conflict.

\section{THE DIALECTICS OF SOCIAL CHANGE}

In a majority of academic and practitioner literature, the relationship between information technology and organizational change is described as deterministic. That is, information technology is treated as an imperative force leading directly to the transformation of social structures and institutions. Recently however, several critical reviews have questioned the deterministic logic underlying such analyses of the organizational consequences of information technology (DeSanctis and Poole, 1994; Markus and Robey, 1988; Orlikowski, 2000; Robey and Boudreau, 1999). In different ways, these authors have provided theoretical tools for understanding the complex relationship between information technology and organizations. Robey and Boudreau (1999) proposed the use of theories employing a dialectical "logic of opposition" to account for the contradictory empirical findings relating information technology to organizational structure. We adopt this perspective to guide our analysis of the case.

Dialectical analysis focuses on contradictions, the relations between them, and the opposites and relations that constitute them. In contrast to a logic of determination, a logic of opposition seeks to explain organizational change by identifying forces both promoting and inhibiting change. There are potentially many theories that can be adapted to incorporate a logic of opposition, including organizational politics, organizational culture, institutional theory, and organizational learning (Robey and Boudreau, 1999). Our focus in this paper is upon organizational politics and institutional theory.

Organizational politics understands organizational change as a process in which social actions taken to transform organizational practices encounter social resistance, which must be overcome before change occurs. Social actions are associated with 
social interests groups, who can enlist information technology to serve their interests. Numerous studies have employed political analysis to examine the implementation of information technology and its role in organizational change (e.g., Franz and Robey, 1984; Markus, 1983). When coupled with appropriate research methodology, organizational politics can resolve contradictory research findings by focusing on political uses of information technology rather than focusing on the technology itself.

Whereas organizational politics explains change with reference to dialectical process within organizations, institutional theory invokes dialectical relationships between organizations and their environments. Specifically, institutional theory proposes that organizational change is informed by historically guided values and norms that tend to stabilize and persist (Powell and DiMaggio, 1991; March and Olsen, 1989). Such historical forces operate at various levels of social analysis including "organizational fields" (Scott, 1995). An organizational field is a recognized area of institutional life that includes relevant actors involved in a common enterprise and who have developed a mutual awareness among them (DiMaggio and Powell, 1983). In economic terms, an organizational field consists of the customers, suppliers, regulatory agencies, and competitors within a particular industry or economic sector. Organizational fields draw social rules, norms and meaning systems from more encompassing levels of analysis such as societal and world systems (Scott, 1995, p. 56). Over the course of time, institutional blueprints for legitimate organizational action become established, creating patterns of regulated social activity.

Although institutional theory's legacy has been to privilege explanations of social stability, contemporary theory is directly interested in explaining organizational change (Oliver, 1991; Scott, 1995). Indeed, the changes associated with globalization that were described in section 2 can be understood as forces emanating from world systems and societal levels of analysis. For example, King and his colleagues (1994) traced the influences of national economic and political changes on the adoption and use of information technologies. As such influences penetrate organizational fields, they stimulate revisions in institutional blueprints and prescribe new expectations for legitimate organizational action (Fox-Wolfgramm, Boal and Hunt, 1998). As these forces for change encounter institutionalized forces for persistence, no clear template for organizational activity emerges. As with organizational politics, dialectical analysis of institutional theory seeks to understand opposing forces rather than to forecast the precise outcomes of dialectical forces in motion.

\section{METHOD}

We designed this research as an interpretive case study that generated qualitative data for analysis and interpretation (Orlikowski and Baroudi, 1991; Walsham, 1995). The primary interest was to trace the implementation of an OLAP tool for conducting detailed analyses of the municipal budget of Umeå. Fieldwork lasted for 37 months, between December 1996 and December 1999, during which 35 interviews were conducted at different levels in the organization. The interviews were all taped and the tapes were transcribed. Participant observation was also used as a data collection 
technique, and one of the authors was granted permission to participate in the organization's daily activities. As the project evolved, the researcher became closer to the organizational members and his influence in the organization increased. According to the classification of Adler and Adler (1994), the researcher's role resembled that of a peripheral-member-researcher because the researcher interacted closely enough with the actor groups to establish a perspective similar to that of an insider. However, the researcher did not take on formal work responsibilities but rather tried to provoke ideas and inspire people to reflect on their actions (Astley and Zammuto, 1992). Document analysis of meeting protocols and technical documentation was also used to confirm the accuracy of data generated by interviews and observation. No systematic content analysis of the documents was conducted.

\section{RESULTS}

The first two paragraphs of this paper set the stage for the case study reported here. The political controversy in Umeå actually began when new City Manager Jan Björinge sought to make local government more fiscally responsible. Although budgets for municipal departments had existed for decades, deviations from budgets were not only common but also tolerated. Moreover, the reasons for deviations were rarely analyzed or understood. Pledged to reform this system, Björinge told department managers that they would lose their jobs if they did not keep within their budgets. Commenting on the new guidelines to reporters from the local newspaper, Björinge was quoted saying that department managers must take cost overruns seriously: "If a manager cannot take this responsibility it is better that he leaves his job" (Hörnfeldt, 1999).

Information technology played a key role in the controversy in Umeå. In December 1996, one of the department managers assumed leadership over a project to implement Powerplay, an OLAP tool designed to allow municipal managers to track expected and actual costs. (A brief overview of the OLAP tool is described in the Appendix.) Department managers used Powerplay to "drill down" into financial data to discover precise reasons for budget deviations. This more careful scrutiny led managers to become more aware of cost overruns and means for reducing them.

As Powerplay developed over the next three years in Umeå, the tool first enabled civil servants and then elected politicians to analyze the city's financial budget. Although city departments were the initial users of Powerplay, politicians later became involved as users of an Intranet version of the system. Accountants in each department placed financial data in web-based reports that the politicians could study at home using a browser. The politicians had access to both historical and current financial data.

The Powerplay project commenced when project initiators identified two pervasive problems in the municipal organization: untimely information for decision-making purposes and information overload. The initiators wanted to increase the quality of the accounting work, and Powerplay was seen as a way to create a better understanding of the financial matters. As the project progressed, more organizational members became 
involved in the effort. Different versions of Powerplay were developed to satisfy the needs of each successive group of users. For example, the department controllers wanted special capabilities for presenting data and different levels of security access to data in the system (thus preserving the integrity of stored data). The politicians demanded that financial data be more accessible to support decision-making, and they demanded that the technology be user friendly so that those without extensive experience using computer applications could use Powerplay. Politicians also stressed that the technology should be a part of a democratization project, meaning that more people in the organization - perhaps even the public - should have access to critical data.

As support for the Powerplay project gathered momentum, new stakeholders found that it was in their best interests to support the effort because the department controllers, the politicians, and the financial units all regarded Powerplay as useful. The initiators convinced most organizational users that work would become easier and more integrated because the standardized key ratios would help organizational members to agree on definitions used when discussing economic issues. The economic situation would be clearer, and it was widely believed that this clarity would affect decisions throughout the organization.

Thus, stakeholders throughout the organization advocated the technology, and only minor arguments were raised against the project. For example, some of the department controllers argued that they had inadequate training on Powerplay. However, arguments against the project were minor, and the use of the Powerplay was supported widely within the organization. Three years following its introduction, Powerplay was being used to fulfill the city manager's mandate to operate within budget.

However, the stricter budgets and proposals to cut costs precipitated the protests of citizens in late November 1999. Umeå's mayor remarked publicly that the controversy was surprising, but that citizen participation was an important part of a well-working democracy. In response to the demonstrations, politicians revised the 2000 budget proposal to be less severe than initially planned. They also promised to investigate the feasibility of extending a public version of Powerplay to citizens over the Internet, thereby increasing their awareness of their local government's financial performance. The logic behind this proposal was to expand the information underlying decisions about public services. In contrast to past practices that hid decision processes from the public, the new proposal would make government decision making more transparent to the citizens. It would also allow them to see the costs of the services that they had traditionally enjoyed. Equipped with such information, it was conceivable that the citizens of Umeå would become more informed participants in the democratic process. By revealing the cost of violin lessons and other community services, for example, Powerplay could enable the public to participate more effectively in discussions about their relative value to the community. 


\section{DISCUSSION}

Powerplay's implementation and consequences in the municipality of Umea demonstrate that an application of advanced information technology can be implemented smoothly at the organizational level, yet encounter resistance in its broader, institutional context of use. At the organizational level, the initiators who promoted Powerplay anticipated potential opposing forces, and implementation was assured by the practice of tailoring Powerplay's features to the requirements of each successive stakeholder group. Within three years of its introduction, therefore, Powerplay was being used to perform sophisticated and detailed economic analyses that placed public decisions on a more solid economic foundation. However, as the citizens of Umeå learned of the consequences of those more rational decisions, they introduced new opposition. In response to the public protests over the use of Powerplay, Umeå's politicians began to consider proposals for making budgetary information more accessible to the public.

At the organizational level of analysis, the case illustrates how forces promoting transformation can overcome forces opposing information technology and its social implications. By anticipating sources of opposition and negotiating measures to satisfy stakeholder opposition, technology initiators built alliances that strengthened the momentum of the change effort. Because initiators held positions as department controllers in accounting and human resources, rather than top management positions, they routinely encountered every facet of organizational life. This allowed them to anticipate potential sources of opposition and to formulate their strategy for overcoming them. As a result of these efforts, Powerplay was successfully implemented and used in the organization.

At the institutional level of analysis, however, a contradictory outcome was realized. Although initiators were indirectly influenced by the global mandate of greater efficiency, they did not anticipate the forces that ultimately opposed this mandate. Initiators of the Powerplay project did not address the sentiment (expressed quietly to the researcher by some organizational members) that using economic criteria for decisions would threaten to displace social decision criteria. As the project progressed, the absence of public opposition can be explained by the project's relative isolation from public scrutiny. However, as soon as the consequences of Powerplay's use became public, institutional opposition was expressed in dramatic fashion.

Why would public opposition to the use of Powerplay be so strong? Do not citizens themselves recognize the need for economic criteria inspired by globalization? To some extent they might, but their opposition was deeply rooted in institutionalized notions about government's societal role. Public sector activities in Sweden need to be understood in the institutional context of a "womb-to-tomb" welfare state. Between the 1940s and 1960s, social democracy was delivered through an expansion of services available on an equal basis for all citizens. Solutions to societal problems were devised centrally, grand in scale, and bore an enormous tax burden. Given this institutional context, citizens in Sweden came to expect "free" social services, 
including violin lessons for their children. Under the contemporary pressures of globalization, however, the allocation of funds to the public sector fell, leading to the use of more economic criteria in public decisions.

At a policy level, the forces for change and the forces for persistence encounter each other on a regular basis, informing specific conflicts such as those described in our case study. The values imprinted on public organizations from years of social democracy do not change overnight, and citizens continue to expect service levels consistent with historically institutionalized values. However, contemporary economic realities are not easy to ignore. Thus, the opposing pressures for economic homogenization and local cultural diversity, which form one of the key issues in the globalization debate (Walsham, 2001), are played out in the decision processes of local governments and other organizations in various parts of the world. It is clear that global homogenization tends to privilege economic considerations to the point of driving noneconomic consideration out (Beck, 2000). Thus, the preservation of local cultural diversity depends upon opposition such as that raised by the citizens of Umeå. We have conceived their voices as institutional forces rooted in social traditions dating back more than 50 years.

The issues raised above are complicated in public organizations by the absence of explicit market mechanisms to determine the value of alternative services. Because the OLAP tool deals only with the cost of services, the value of those services must be inferred by organizational members. Tools like Powerplay may reveal the costs of services in minute detail, yet they are necessarily mute regarding the social value attached to those services. Despite this complication, public organizations adopt the vocabulary that allows stakeholders to communicate in economic terms. Following Powerplay's implementation, arguments within Umeå's municipal organization for and against proposed courses of action required economic justification. Outside, in the wider organizational field, stakeholders continued to evaluate those decisions according to decades-old values that had come to define Swedish life. The disconnection between cost and value reflects one of the central tensions in globalization.

Applying a logic of opposition at both the organizational and institutional levels allows us to understand the social contexts of attempts to transform organizations with information technology. Rather than expecting direct, deterministic effects of implementation, we look for opposition and resistance. As our analysis shows, opposition is not confined to the organization, and forces designed to overcome opposition may be ineffective if focused only on political opposition from recalcitrant users. As Umeå's managers eventually learned, public opposition is based on institutionalized values with considerable historical weight. Institutional issues pose more serious concerns that Umeå and other cities must find ways to confront. 


\section{CONCLUSION}

We have analyzed the case of Powerplay's implementation in Umea to illustrate how forces in opposition affect information technology's social consequences. In this exercise, we have not taken sides, that is, we have not seen the initiators of Powerplay as the "good guys" and the resistors as "bad." In our conclusion, however, we wish to comment on the importance of information technology's role in the management of public organizations beset by the pressures of globalization. As noted earlier, globalization itself constitutes a set of conflicting forces. On the one hand, local governments are pressured to be more efficient and economic in order to preserve their competitive positions in a world economy. On the other hand, local governments must mediate global pressures by formulating policies that are in part designed to preserve distinct social traditions and practices. Thus, it is not always a reasonable solution to capitulate to the need to run small cities like a global enterprise. Nor is it reasonable to isolate local governance from the world at large.

One obvious implication from our study is the need for all parties implicated in the change process to look closely at the forces promoting change as well as forces promoting persistence. Although information technologies may be portrayed by some as the key enablers of social transformation, their actual consequences emerge from complex processes involving opposing forces. A logic of opposition helps to problematize the transformational agenda so that more realistic solutions will be sought. Moreover, the source of opposing forces is not always obvious, as the managers in Umeå eventually realized. Our analysis shows the value of using theories that implicate multiple levels of social analysis in explaining organizational changes related to information technology.

Incorporating technologies into management practices, whether in the public or private sector, has never been a straightforward exercise with all positive consequences. Therefore, those charged with making public organizations more responsive to global pressures need to recognize the complexity of the task before them. The adoption of corporate discourse in government is one facet of a pervasive new market-driven ethos that critically evaluates the cost of every service produced. Left unchecked, this ethos privileges the measurable over the intangible, and the economic costs of production over the social value of services consumed. In doing so, it neglects the traditional function of the public organization and potentially undermines its social role.

We conclude by observing that information technologies are not inconsistent with the goal of preserving democratic governance in the face of global pressures to make governments more efficient. However, preserving democracy requires attention to organizational and institutional processes discussed earlier. We left Umeå's mayor and city managers contemplating a proposal to create an Internet-accessible version of Powerplay that would give citizens access to municipal budget data. Although a tool like Powerplay might seem to threaten democracy by supporting business-like decisions to limit social services, it may also enhance public participation in the 
democratic process. By providing citizens detailed and relevant information about the costs of public services, information technologies may enhance democratic process. Informed citizens can engage in more meaningful dialogues with public servants and politicians that were formerly infeasible. Citizen participation has never depended on information technology, yet information technologies can enhance the democratic process by making government more transparent. As the basis for democratic decisions moves from the dark into the light, information technology will have played an important role.

\section{REFERENCES}

Adler, P.A., and Adler, P. (1994). "Observational Techniques," in Denzin, N. K., and Lincoln, Y.S. (eds.), Handbook of Qualitative Research. Thousand Oaks, CA: Sage.

Astley, W.G., and Zammuto, R. (1992). "Organization Science, Managers and Language Games," Organization Science, 3, 443-460.

Beck, U (2000). What is Globalization? Cambridge: Polity Press.

Castells, M. (1996). The Rise of the Network Society. London: Blackwell Publishers.

Castells, M. (1997). The Power of Identity. London: Blackwell Publishers.

Deetz, S (1992). Democracy in an age of corporate colonization. Albany: State University of New York Press.

DeSanctis, G., and Poole, M.S. (1994). "Capturing the Complexity in Advanced Technology Use: Adaptive Structuration Theory," Organization Science, 5, 121-147.

Dicken, P. (1992). Global Shift: The Internationalisation of Economic Activity. London: PCP.

DiMaggio, P.J., and Powell, W.W. (1983). "The Iron Cage Revisited: Institutional Isomorphism and Collective Rationality in Organizational Fields," American Sociological Review, 48, 147-160.

Fox-Wolfgramm, S.J., Boal, K.B., and Hunt, J.G. (1998). "Organizational Adaptation to Institutional Change: A Comparative Study of First-Order Change in Prospector and Defender Banks," Administrative Science Quarterly, 43, 87-126.

Franz, C.R., and Robey, D. (1984). "An Investigation of User-Led System Design: Rational and Political Perspectives," Communications of the ACM, 27, 1202-1209.

Holmström, J. (2000). Information System and Organization as Multipurpose Network, Doctoral Dissertation: Umeå University.

Hörnfeldt, K. (1999). "Kärvt budskap från Björinge" (Harsh message from Björinge), Västerbottens-Kuriren, November 12, 17. Author translation. 
King, J.L., Gurbaxani, V., Kraemer, K.L., McFarlan, F.W., Raman, K.S., and Yap, C.S. (1994). "Institutional Factors in Information Technology Innovation," Information Systems Research, 5, 139-169.

March, J.G., and Olsen, J.P. (1989). Rediscovering Institutions: The Organizational Basis of Politics. New York: Free Press.

Markus, M.L. (1983). "Power, Politics, and MIS Implementation," Communications of the ACM, 26, 430-444.

Markus M.L., and Robey, D. (1988). "Information Technology and Organizational Change: Causal Structure in Theory and Research," Management Science, 34, 583-598.

Oliver, C. (1991). "Strategic Responses to Institutional Processes," Academy of Management Review, 16, 145-179.

Orlikowski, W.J. (2000). "Using Technology and Constituting Structures: A Practice Lens for Studying Technology in Organizations," Organization Science, 11, 404-428.

Orlikowski, W.J., and Baroudi, J.J. (1991). "Studying Information Technology in Organizations: Research Approaches and Assumptions," Information Systems Research, 2, 128.

Powell, W.W., and DiMaggio, P.J. (eds) (1991). The New Institutionalism in Organizational Analysis, Chicago: The University of Chicago Press.

Robey, D., and Boudreau, M-C. (1999). "Accounting for the Contradictory Organizational Consequences of Information Technology: Theoretical Directions and Methodological Implications," Information Systems Research, 10, 167-185.

Robey, D., and Boudreau, M-C. (2000). "Organizational Consequences of Information Technology: Dealing with Diversity in Empirical Research," in R.W. Zmud (ed.), Framing the Domains of IT Management: Projecting the Future...through the Past, Cincinnati, OH: Pinnaflex, 51-63.

Scott, R. W. (1995). Institutions and Organizations, Thousand Oaks, CA: Sage.

Van de Ven, A.H., and Poole, M.S. (1995). "Explaining Development and Change in Organizations," Academy of Management Review, 20, 510-540.

Walsham, G. (1995). "Interpretive Case Studies in IS Research: Nature and Method," European Journal of Information Systems, 4, 74-81.

Walsham, G. (2001). Making a World of Difference: IT in a Global Context, Chichester, UK: Wiley.

Walsham, G., and Sahay, S. (1999). "GIS for district-level administration in India: Problems and opportunities," MIS Quarterly, 23, 39-66. 
Daniel Robey is Professor and John B. Zellars Chair of Information Systems at Georgia State University, holding a joint appointment in the Departments of Computer Information Systems and Management. He teaches courses on Qualitative Research Methods in Information Systems and Information Technology and Organizational Transformation. He earned his doctorate in Administrative Science in 1973 from Kent State University. Professor Robey is Editor-in-Chief of Information and Organization, Senior Editor of MIS Quarterly and serves on the editorial boards of Organization Science, Information Technology \& People, and the John Wiley series on Information Systems. Professor Robey is the author of three books and numerous articles in such journals as Management Science, Organization Science, Information Systems Research, MIS Quarterly, Human Relations, Journal of Management Information Systems, ACM Transactions on Information Systems, Information Systems Journal, Academy of Management Review, Academy of Management Journal, Information Technology \& People, and Decision Sciences. His current research includes empirical examinations of the effects of a wide range of technologies on organizational structure and patterns of work. It also includes the development of theoretical approaches to explaining the development and consequences of information technology in organizations.

Jonny Holmström is an assistant professor at the Center for Digital Business and Department of Informatics, Umeå University, and the Viktoria Institute, Göteborg. Professor Holmström holds a Ph.D. from Umeå University, where his dissertation research focused on the organizational issues involved in the adoption of IT. His research interests include IT's organizational concequences, and the adoption of electronic commerce innovations. His work has appeared in journals such as Information and Organization and Scandinavian Journal of Information Systems. 